\begin{tabular}{|l|l|l||}
\hline \multicolumn{2}{|c|}{ PublisherInfo } \\
\hline \hline PublisherName & $:$ & BioMed Central \\
\hline \hline PublisherLocation & $:$ & London \\
\hline \hline PublisherImprintName & $:$ & BioMed Central \\
\hline \hline
\end{tabular}

\title{
Prognostic value of ultrasonographic measurements in stable angina
}

\begin{tabular}{|l|l|l||}
\hline \multicolumn{2}{|c||}{ ArticleInfo } \\
\hline \hline ArticleID & $:$ & 30 \\
\hline \hline ArticleDOI & $:$ & $10.1186 /$ cvm-2001-72105 \\
\hline \hline ArticleCitationID & $:$ & 72105 \\
\hline \hline ArticleSequenceNumber & $:$ & 9 \\
\hline \hline ArticleCategory & $:$ & Paper Report \\
\hline \hline ArticleFirstPage & $:$ & 1 \\
\hline \hline ArticleLastPage & $:$ & 3 \\
\hline \hline & & RegistrationDate $: 2001-10-18$ \\
ArticleHistory & $:$ & $\begin{array}{l}\text { Received } \\
\text { OnlineDate } \quad: 2001-2-15\end{array}$ \\
\hline \hline ArticleCopyright & $:$ & Biomed Central Ltd2001 \\
\hline \hline
\end{tabular}




\begin{tabular}{|l|l|l|}
\hline ArticleGrants & $:$ & \\
\hline \hline ArticleContext & $:$ & 1306322 \\
\hline
\end{tabular}

Joanna Lyford, ${ }^{\text {Aff1 }}$

Corresponding Affiliation: Aff1

Aff1 MedWire, UK

Keywords

Coronary disease, plaque, risk factors

\section{Context}

Little has been published concerning the prognostic impact of vascular changes in the peripheral arteries. This study aimed to assess the prognostic impact of femoral plaques, carotid plaques, and intima-media thickness.

\section{Significant findings}

Carotid intima-media thickness and plaques were related to the risk of CV death or MI. Femoral intima-media thickness was related to $\mathrm{CV}$ death and $\mathrm{MI}$, as well as to revascularization, while femoral plaques were only related to the latter. After adjustment for age, sex, smoking, previous CV disease, and lipid status, carotid intima-media thickness failed to predict any CV event, while carotid plaques tended to predict the risk of $\mathrm{CV}$ death or MI $(P=0.056)$. Femoral intima-media thickness and plaques were still related to the risk of revascularization after adjustment $(P<0.01$ and $P<0.05$, respectively), although the relationship was weaker. The risk of coronary events increased in proportion to the severity of the plaques, and was more than double in patients with the most severe plaques, compared with healthy counterparts.

\section{Comments}


A study of the prognostic accuracy of vascular ultrasonography finds that carotid and femoral vascular changes are differently related to $\mathrm{CV}$ events. The researchers conclude that evaluations of plaques are better predictors than assessments of intima-media thickness, and that carotid plaques are related to $\mathrm{CV}$ death or nonfatal MI while femoral plaques are related to revascularization. Their results suggest that intima-media thickness is a less sensitive surrogate variable for the risk of coronary events than the presence of plaques; however, in patients without known CAD there are fewer plaques so intima-media thickness may be a more useful predictor of risk.

\section{Methods}

A total of 809 patients with stable angina pectoris were studied prospectively during double-blind treatment with verapamil or metoprolol. A subgroup of 558 subjects (182 female, mean age 60?7 years) underwent baseline ultrasonographic assessments of intima-media thickness, lumen diameter, and carotid and femoral artery plaques. After a mean follow-up period of three years, Cox regression analysis was used to identify predictors of CV events (death, nonfatal MI or revascularization).

\section{Additional information}

\section{References}

1. Held C, Hjemdahl P, Eriksson SV, Bjorkander I, Forslund L, Rehnqvist N: Prognostic implications of intima-media thickness and plaques in the carotid and femoral arteries in patients with stable angina pectoris. Eur Heart J . 2001, 22: 62-72. 